Abstracta Iranica Abstracta Iranica

Revue bibliographique pour le domaine irano-aryen

Volume 26 | 2005

Comptes rendus des publications de 2003

Aux sources de Shéhérazade. Contes et coutumes des
femmes zoroastriennes. Louvain, Peeters, Acta
Iranica, 2003, 576 p., 191 ill.

Philippe Rochard

(2) OpenEdition

Journals

Édition électronique

URL : http://journals.openedition.org/abstractairanica/921

ISSN : 1961-960X

Éditeur :

CNRS (UMR 7528 Mondes iraniens et indiens), Éditions de l'IFRI

Édition imprimée

Date de publication : 15 mai 2005

ISSN : 0240-8910

Référence électronique

Philippe Rochard, «Aux sources de Shéhérazade. Contes et coutumes des femmes zoroastriennes. Louvain, Peeters, Acta Iranica, 2003, 576 p., 191 ill. », Abstracta Iranica [En ligne], Volume 26 | 2005, document 464, mis en ligne le 18 novembre 2005, consulté le 25 septembre 2020. URL : http:// journals.openedition.org/abstractairanica/921

Ce document a été généré automatiquement le 25 septembre 2020.

Tous droits réservés 


\title{
Aux sources de Shéhérazade. Contes et coutumes des femmes zoroastriennes. Louvain, Peeters, Acta Iranica, 2003, 576 p., 191 ill.
}

\author{
Philippe Rochard
}

1 L'objectif de cet ouvrage magistral, qui va faire date dans les études zoroastriennes, était, pour reprendre les termes de l'A., «d'analyser le dire d'un conte comme une technique à part entière ». L'A. a méticuleusement collecté puis analysé, entre 1991 et 2001 , les rites et les contes féminins zoroastriens d'Inde et d'Iran qui sont au cœur des cérémonies domestiques des sofre. L'A. reprend à son compte la question de Jean Dominique Lajoux : «Les chercheurs qui travaillent sur le conte ont-ils jamais associé l'étude des gestes et des mimiques d'une conteuse à l'analyse structurale du texte de la même histoire ? N'y a-t-il pas dans les gestes qui accompagnent le récit, l'explication de certaines ambiguïtés voulues du langage? » (p. 150, note 26). A travers cette volonté de déterminer si, oui ou non, des gestes codifiés appuient les contes, les commentent, les prolongent et les nuancent, nous retrouvons l'influence de Geneviève Calame-Griaule et son intérêt pour «l'étude des gestes narratifs » et « le langage gestuel des conteurs » (p. 197) et celle de Radcliffe-Brown (p. 201, note 74) pour l'étude des récits légendaires.

2 Le corpus recueilli dans le monde zoroastrien, intégralement présenté (ch. 1 «Inventaire des contes féminins dans la tradition zoroastrienne » pp. 21-127), a pour obj ectif d'explorer cette hypothèse. L'A. relève que les contes (Bïbi sešanbe, Moškel gošă... ) qui mettent en scène les fées domestiques zoroastriennes, font l'objet d'une double ritualisation: dans les registres de la mise en scène sonore (débit saccadé scandé sur le mode des hymnes avestiques) et de la mise en scène visuelle (récitation préludant à un sacrifice des offrandes disposées sur l'autel domestique à la manière des rituels sacerdotaux).

3 Ces distinctions scénographiques fort utiles pour apprécier le double impact des contes - matériel oral mais aussi son déploiement dans l'espace, un aspect trop souvent 
négligé des folkloristes - sont empruntées à Claudine et Xavier de France, deux ethnologues-cinéastes inspirés par Leroi-Gourhan et responsables de la formation de Recherches Cinématographiques de Paris X où Eric Phalippou a été formé. L'A. utilise donc toutes les ressources de sa double formation de cinéaste-ethnologue et d'iraniste pour appréhender son sujet, privilégiant tantôt la première dans son chap. 2 « Analyse des sofre grâce au support du film ethnographique» (pp. 129-233), tantôt la seconde dans le chap. 3 "Herméneutique des sofre au moyen de l'anthropologie religieuse comparée » (pp. 235-333). Il opère la synthèse de ces deux méthodes dans le chap. 4 "Les sofre, éléments d'un tripartisme religieux, social et littéraire " (pp. 335-430) et peut ainsi restituer à ces contes la place qui, selon lui, leur incombe dans la société iranienne.

L'ouvrage laisse apparaître une belle vivacité du regard, beaucoup d'humour, et fait preuve d'une impressionnante érudition qui non seulement permet à l'A. de maitriser ses objectifs tout en ouvrant de nombreuses pistes mais aussi, par ses notes parfois provocatrices, suscitera à n'en pas douter de nombreux débats. Le lecteur sera quelquefois dérouté par l'abondance des notes, aussi importantes que le texte et empêchant toute lecture rapide de l'ouvrage. Mais la patience étant récompensée à chaque page par quelques géniales trouvailles, et l'A. ayant promis de faire par la suite des articles de synthèse, en définitive, on se laissera volontiers séduire par ce diable de conteur jusqu'à tard dans la nuit. Car au-delà du thème central, Eric Phalippou nous offre à la fois une vision de la communauté des «İrānī » de Bombay face à ses voisins Hindou, Parsi et Musulman, une réflexion sur la place de l'ethnologue vis-à-vis de son objet de recherche, une analyse comparative avec les fonds folkloriques européens et les prémisses d'un travail à venir sur l'impact du zoroastrisme dans les sociétés occultes qui «clouent" littéralement le lecteur à son fauteuil. Le tout est servi par une iconographie précise et de grande qualité, œuvre de l'épouse de l'A. et photographe professionnelle de son état, Martine Phalippou, à qui l'A. rend un éloge aussi vibrant que mérité.

\section{INDEX}

Mots-clés : femmes zoroastriennes, anthropologie religieuse, contes féminins

Keywords : Zoroastrian women, religious anthropology, women tales

Thèmes : 16.1. Iran

\section{AUTEURS}

PHILIPPE ROCHARD

Université Marc Bloch - Strasbourg 